\title{
Virulence plasmid-associated sensitivity to acid in Escherichia coli and its possible significance in human infections
}

\author{
G. E. COOPER and R. J. ROWBURY
}

Department of Botany and Microbiology, University College London, Gower Street, London WC1E 6BT

\begin{abstract}
Summary. Several strains of Escherichia coli were markedly sensitised to killing at $p \mathrm{H}$ 2.5 or 3.5 when the ColV,I-K94 virulence plasmid was introduced into them. For strain 1829 , the effect on acid sensitivity was due to the presence of plasmid in the previously resistant strain rather than to its introduction into an acid-sensitive variant already in the population. Acid sensitivity was also conferred by the ColV-K30 and ColB-K98 plasmids and the resistance plasmid R124-F2; other plasmids tested had no marked effect. Studies of $\mathrm{ColV}^{+}$strains carrying mutant plasmids indicated that it was the presence of ColV-encoded transfer components that made ColV,I-K94 ${ }^{+}$strains acidsensitive. Organisms in the exponential phase of growth were more sensitive to acid than were those from stationary phase cultures and this difference was more marked for ColV,I-K94+ ${ }^{+}$strains than for $\mathrm{Col}^{-}$ones. Moreover, $\mathrm{ColV}^{+}$strains exposed to conditions of low $p \mathrm{H}$ for short periods subsequently grew less well than the $\mathrm{Col}^{-}$ parent and appeared to be sensitised by the damage to the effects of $\mathrm{H}_{2} \mathrm{O}_{2}$. These results indicate that some $\mathrm{ColV}^{+}$strains may be more sensitive to gastric acid and to phagocytic acidity than are $\mathrm{Col}^{-}$strains. ColV,I-K94 ${ }^{+}$strains grew as well as $\mathrm{Col}^{-}$ ones in broth or urine at $p \mathrm{H} \mathrm{4.5-6.0} \mathrm{which} \mathrm{suggests} \mathrm{that} \mathrm{the} \mathrm{presence} \mathrm{of} \mathrm{the} \mathrm{plasmid}$ would not be detrimental to bacterial growth in the urinary tract. The presence of transfer components in the outer membrane of ColV,I-K94+ bacteria may destabilise the lipopolysaccharide layer allowing increased penetration of hydrogen ions.
\end{abstract}

\section{Introduction}

Plasmids of the ColV group are large elements that confer F-like transfer properties on enterobacteria that harbour them. Such transfer is derepressed for many of these elements (Hardy, 1975) although transfer efficiency can be greatly reduced by the presence of $\mathrm{fin}^{+}$plasmids. ColV plasmids also permit the organisms to synthesise the colicin $\mathrm{V}$ toxin, its immunity component (and, frequently, colicin Ia and its immunity component) and the VmpA outer membrane protein (Moores and Rowbury, 1982; Rowbury et al., 1985).

The virulence-enhancing effect of ColV plasmids on enterobacteria probably results from several different properties. First, ColV plasmids increase the serum resistance of Escherichia coli strains, allowing them to survive the effects of complement (Williams Smith, 1974; Binns et al., 1979 and 1982; Taylor, 1983). Second, some ColV plasmids encode the aerobactin iron chelation system (Williams,

Received 15 Jan. 1986; accepted 25 Feb. 1986.

Please address all correspondence to Dr R. J. Rowbury.
1979) which permits growth in iron-depleted serum and confers greater resistance to phagocytic killing (because the organisms are able to maintain their catalase activity). Third, the presence of a ColV plasmid enables the organism to attach to host cells (Clancy and Savage, 1981), perhaps because of increased hydrophobicity of the surface of $\mathrm{ColV}^{+}$ organisms (Tewari et al., 1985). Furthermore, the autoagglutination of $\mathrm{ColV}^{+}$strains may enhance survival in the animal host (Rowbury et al., 1985).

Strains harbouring Colv plasmids have been isolated from patients with serious intestinal infections (Fredericq and Joiris, 1950). Moreover, ColV plasmids can enhance invasiveness (Williams Smith, 1974; Williams Smith and Huggins, 1976) and $\mathrm{ColV}^{+}$organisms are often responsible for systemic infections in livestock and urinary tract infections in man.

To reach and multiply in the intestine, ingested organisms must survive exposure to gastric acid (c. $p \mathrm{H} 2$ ). An organism which subsequently invades the tissues and bloodstream from the intestine will then be subjected to attack by phagocytes, within the 
phagolysosomes of which, $p \mathrm{H}$ values of $3 \cdot 5-4 \cdot 5$ or less can be achieved (Jensen and Bainton, 1973; Mims, 1982; Rous, 1925). Few enterobacteria will multiply at $p \mathrm{H} 4.5$ but the ability of phagocytosed organisms to survive this acidity might aid pathogenicity if lysis of the phagocyte allowed release of viable organisms. Potential pathogens also have to resist acid in the vagina, where $p \mathrm{H}$ values of $c .5 \cdot 0$ 5.5 are produced by commensal lactobacilli, and in urine, where similar $p \mathrm{H}$ values are found. The growth rates of most pathogens would be markedly reduced at such $p \mathrm{H}$ values. Changes in acid sensitivity associated with introduction of ColV plasmids may, therefore, be relevant to pathogenicity of $\mathrm{ColV}^{+}$strains and we have examined this possibility.

\section{Materials and methods}

\section{Bacterial strains}

All strains were derivatives of $E$. coli K12. The characteristics of strains 1829, P678-54 and 1157 have been described previously (Tewari et al., 1985). The ColV,I-K94 ${ }^{+}$strains and derivatives of strain 1829 carrying other plasmids were prepared by plasmid transfer from E. coli J53 (Moores and Rowbury, 1982; Tewari et al., 1985); in one case, ColV,I-K94 was introduced into $E$. coli strain 1829 by transformation (Tewari et al., 1985). E. coli strain $1829 \mathrm{ColV}, \mathrm{I}-\mathrm{K} 94$ was cured of plasmid carriage by growth at elevated temperature (Rowbury et al., 1985).

\section{Grow'th media and culture conditions}

Nutrient Broth (Oxoid No. 2, $25 \mathrm{~g} / \mathrm{L}$ ), solidified as required with $2 \% \mathrm{w} / \mathrm{v}$ Bacto Agar (Difco), was used; the $\mathrm{pH}$ of broth media was appropriately adjusted with lactic acid.

For growth tests in urine. pooled freshly voided samples from men were filtered through $1 \cdot 2-\mu \mathrm{m}$ pore size membrane filters and adjusted to the appropriate $p \mathrm{H}$ with lactic acid or $\mathrm{NaOH}$.

Unless otherwise stated, organisms were grown to exponential phase with shaking.

\section{Acid treatment}

For tests of viability at $p \mathrm{H} 2 \cdot 5$ or $3 \cdot 5$, organisms were diluted into broth acidified with $\mathrm{HCl}$ and incubated for the required period at $37 \mathrm{C}$. Treated organisms were then diluted with $0.05 \mathrm{M}$ Tris- $\mathrm{HCl}$ buffer $(p \mathrm{H} \mathrm{7.5)}$ and samples plated on nutrient-agar plates and incubated at $37^{\circ} \mathrm{C}$.

Growth of organisms exposed to $\mathrm{pH} 2.5$ or 3.5 in broth was also investigated. After the appropriate length of exposure, organisms were diluted into fresh broth, the $p \mathrm{H}$ was adjusted to $7 \cdot 35-7 \cdot 4$ and incubation was continued with shaking at $37^{\circ} \mathrm{C}$. Samples were taken at intervals for optical density measurement at $520 \mathrm{~nm}$. Some of the acidtreated samples were subsequently exposed to hydrogen peroxide $(2.5 \mathrm{~mm})$; after the required exposure to $\mathrm{H}_{2} \mathrm{O}_{2}$ organisms were harvested, resuspended in fresh broth and re-incubated as above.

\section{Results}

Sensitivity of E. coli strains to $\mathrm{pH} 2 \cdot 5$

The presence of the ColV,I-K94 plasmid greatly increased the sensitivity of $E$. coli strain 1829 to killing at $p \mathrm{H} 2.5$ (fig. 1). Similar effects were seen with $E$. coli strains 1157 and P678-54 (table I). Another ColV plasmid (ColV-K30) also markedly increased the acid sensitivity of $E$. coli strain 1829 whereas a cured derivative of strain 1829 ColV,IK94 was as resistant as strain 1829 itself (table I).

Acid sensitivity of organisms harvested from exponential-phase cultures was greater than that of organisms harvested from stationary-phase cultures for both ColV,I-K $94^{+}$organisms and for their $\mathrm{Col}^{-}$parent, but the difference between stationary and exponential cells was greater for the ColV,I-

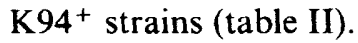

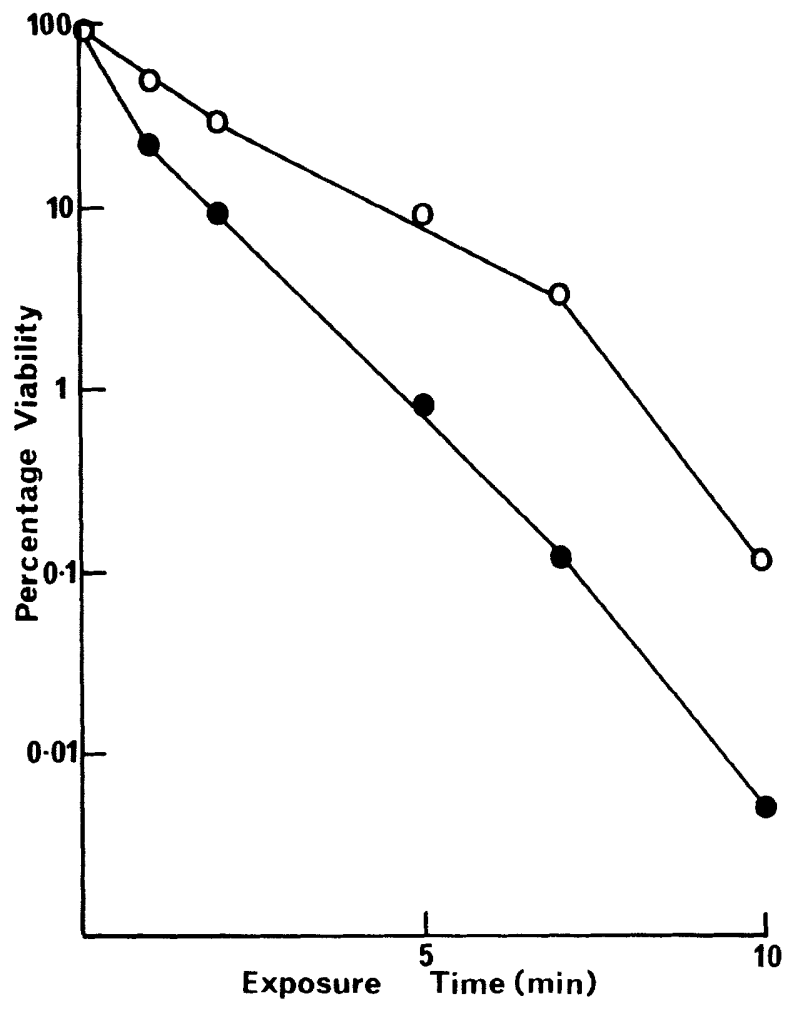

Fig. 1. The sensitivity of $E$. coli strains 1829 and 1829 ColV,I$\mathrm{K} 94$ to $\mathrm{pH} 2 \cdot 5 . \mathrm{O}=$ strain $1829 ; \bullet=$ strain $1829 \mathrm{ColV}, \mathrm{I}-\mathrm{K} 94$. 
Table I. Effect of ColV plasmids on acid sensitivity

\begin{tabular}{lc} 
E. coli strain & $\begin{array}{c}\text { Percentage viability at } \\
p \mathrm{H} 2 \cdot 5^{*}\end{array}$ \\
\hline 1829 & 100 \\
1829 ColV,I-K94 & 1 \\
1829 ColV-K30 & 0 \\
1829 cured & 115 \\
1829 ColV,I-K94 transformed & 3 \\
1157 & 100 \\
P678-54 ColV,I-K94 & 3 \\
P678-54 ColV,I-K94 & 100 \\
\end{tabular}

* Viability relative to that of the plasmid-free parent $(100 \%)$ after incubation for $10 \mathrm{~min}$ in broth at $p \mathrm{H} \mathrm{2 \cdot 5}$.

Table II. Acid sensitivity of organisms from exponential and stationary phases of growth

\begin{tabular}{lcc}
\hline & \multicolumn{2}{c}{$\begin{array}{c}\text { Percentage survival after exposure } \\
\text { to } p \mathrm{H} 2 \cdot 5 \text { for } 10 \text { min of cells } \mathrm{u}\end{array}$} \\
\cline { 2 - 3 } E. coli strain & Stationary-phase & Exponential-phase \\
\hline 1829 & 27 & $3 \cdot 3$ \\
1829 ColV,I-K94 & 23 & $0 \cdot 2$ \\
1157 & 10 & $0 \cdot 2$ \\
1157 ColV,I-K94 & 5 & $0 \cdot 002$ \\
P678-54 & 42 & 34 \\
P678-54 ColV,I-K94 & 25 & $2 \cdot 2$ \\
& & \\
\hline
\end{tabular}

\section{Effects of other plasmids on acid sensitivity}

A derivative of $E$. coli strain 1829 carrying a mutant form of plasmid ColV,I-K94-ColVM50(1) - which encodes normal colicin components but no transfer components, exhibited acid sensitivity very similar to that of $E$. coli strain 1829 itself, i.e., loss of transfer components led to resistance (table III). In contrast, the presence of plasmid ColV-M40(5), which confers normal transfer properties but no colicin components, made $E$. coli strain 1829 almost as acid-sensitive as strain 1829 ColV,I-K94 (table III).

Several other plasmids were tested for their effects on acid sensitivity when introduced into $E$. coli strain 1829. Plasmid R124-F2, which confers derepressed transfer properties, had a marked sensitising effect whereas Flac had little effect (table III). The resistance plasmid R124 (the parent of plasmid R124-F2) alone had little effect on the acid sensitivity of $E$. coli strain 1829 ; when present with ColV,I-K94, it abolished the effect of the latter
Table III. Plasmid components and acid sensitivity

\begin{tabular}{lllr}
\hline E. coli strain & $\begin{array}{l}\text { Colicin/ } \\
\text { immunity } \\
\text { components }\end{array}$ & $\begin{array}{l}\text { Transfer } \\
\text { components }\end{array}$ & $\begin{array}{c}\text { Percentage } \\
\text { viability } \\
\text { at } p \mathrm{H} 2 \cdot 5^{*}\end{array}$ \\
\hline 1829 & none & none & 100 \\
1829 ColV,I-K94 & V and 1a & derepressed & 3 \\
1829 ColV-M40(5) & none & derepressed & 13 \\
1829 ColV-M50(1) & V and 1a & none & 67 \\
1829 & none & none & 100 \\
1829 ColV,I-K94 & V and 1a & derepressed & 3 \\
1829 Flac & none & derepressed & 70 \\
1829 R124-F2 & none & derepressed & 27 \\
\hline
\end{tabular}

* Relative to E. coli strain $1829(100 \%)$.

Table IV. Repression of transfer properties and acid sensitivity

\begin{tabular}{lllr}
\hline E. coli strain & $\begin{array}{l}\text { Colicin/ } \\
\text { immunity } \\
\text { components }\end{array}$ & $\begin{array}{l}\text { Transfer } \\
\text { components }\end{array}$ & $\begin{array}{c}\text { Percentage } \\
\text { viability } \\
\text { at } p \mathrm{H} \mathrm{2 \cdot 5*}\end{array}$ \\
\hline 1829 & none & none & 100 \\
1829 ColV,I-K94 & V and 1a & derepressed & 11 \\
1829 R124 & none & repressed & 89 \\
1829 ColV,I-K94 R124 & V and 1a & repressed & 89 \\
1829 & none & none & 100 \\
1829 ColV,I-K94 & V and 1a & derepressed & 2 \\
1829 ColB-K98 & B and M & repressed & 13 \\
\hline
\end{tabular}

* Relative to E. coli strain $1829(100 \%)$.

(table IV). The plasmid ColB-K98 markedly increased the acid sensitivity of $E$. coli strain 1829 (table IV).

\section{Effect of ColV,I-K94 at pH $3 \cdot 5$}

For all three $E$. coli strains tested (strains 1829 , 1157 and P678-54), organisms carrying plasmid ColV,I-K94 were markedly more sensitive to killing at $p \mathrm{H} 3.5$ than were the $\mathrm{Col}^{-}$parents. The percentages of $E$. coli strain 1829 and strain 1829 ColV,IK94 cells surviving at $p \mathrm{H} 3.5$ during incubation for $60 \mathrm{~min}$ at $37^{\circ} \mathrm{C}$ are shown in fig. 2.

\section{Growth inhibition after exposure to acid}

Growth rates of organisms were reduced after exposure to either $p \mathrm{H} 2.5$ or $p \mathrm{H} 3.5$ for short periods and the effects were much more marked for ColV ${ }^{+}$ strains than for $\mathrm{Col}^{-}$strains. Fig. 3 shows that, after exposure to $p \mathrm{H} 3.5$ for 12.5 or $16 \mathrm{~min}$ at $37^{\circ} \mathrm{C}$, 


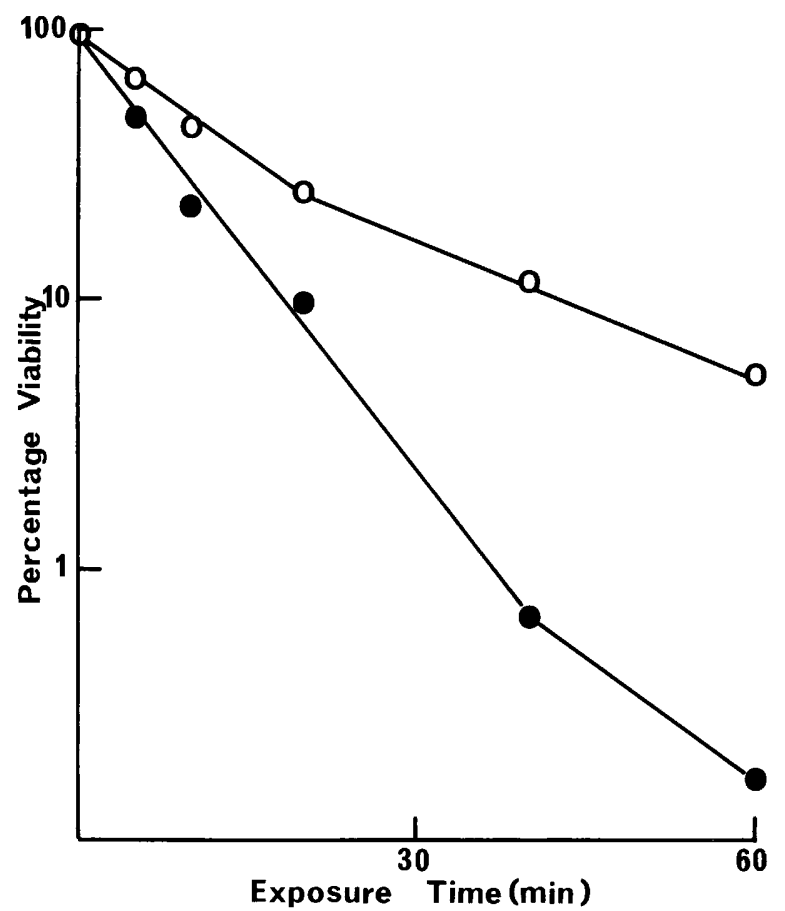

Fig. 2. The sensitivity of $E$. coli strains 1829 and 1829 ColV,I$\mathrm{K} 94$ to $p \mathrm{H} 3 \cdot 5 . \mathrm{O}=$ strain $1829 ; \bullet=$ strain $1829 \mathrm{ColV}, \mathrm{I}-\mathrm{K} 94$.

organisms of E. coli strain 1829 ColV, I-K94 grew less well than those of strain 1829 itself. Similar results were obtained with $E$. coli strain 1157 and P678-54 and their ColV,I-K94+ derivatives.

Organisms surviving damage by acid appeared to be sensitised to growth inhibition by $\mathrm{H}_{2} \mathrm{O}_{2}$ (table $\mathrm{V}$ ).

\section{Growth and multiplication at pH 4.0-6.0}

There was no significant difference between $E$. coli strain 1829 and strain 1829 ColV,I-K94, with respect to growth in broth acidified with lactic acid.

Table V. Sensitisation of $E$. coli strain 1829 ColV,I-K94 to $\mathrm{H}_{2} \mathrm{O}_{2}$ by acid treatment

\begin{tabular}{lr}
\hline Treatment & Growth at $90 \mathrm{~min}^{*}$ \\
\hline None & 100 \\
Acid $+5 \mathrm{~min}$ & 79 \\
$\mathrm{H}_{2} \mathrm{O}_{2} 5 \mathrm{~min}$ & 106 \\
$\mathrm{H}_{2} \mathrm{O}_{2} 10 \mathrm{~min}$ & 115 \\
Acid $5 \mathrm{~min}, \mathrm{H}_{2} \mathrm{O}_{2} 5 \mathrm{~min}$ & 25 \\
Acid $5 \mathrm{~min}, \mathrm{H}_{2} \mathrm{O}_{2} 10 \mathrm{~min}$ & 24 \\
\hline
\end{tabular}

* Percentage of untreated control.

+ Acid treatment, $p \mathrm{H} \mathrm{3 \cdot 5.}$

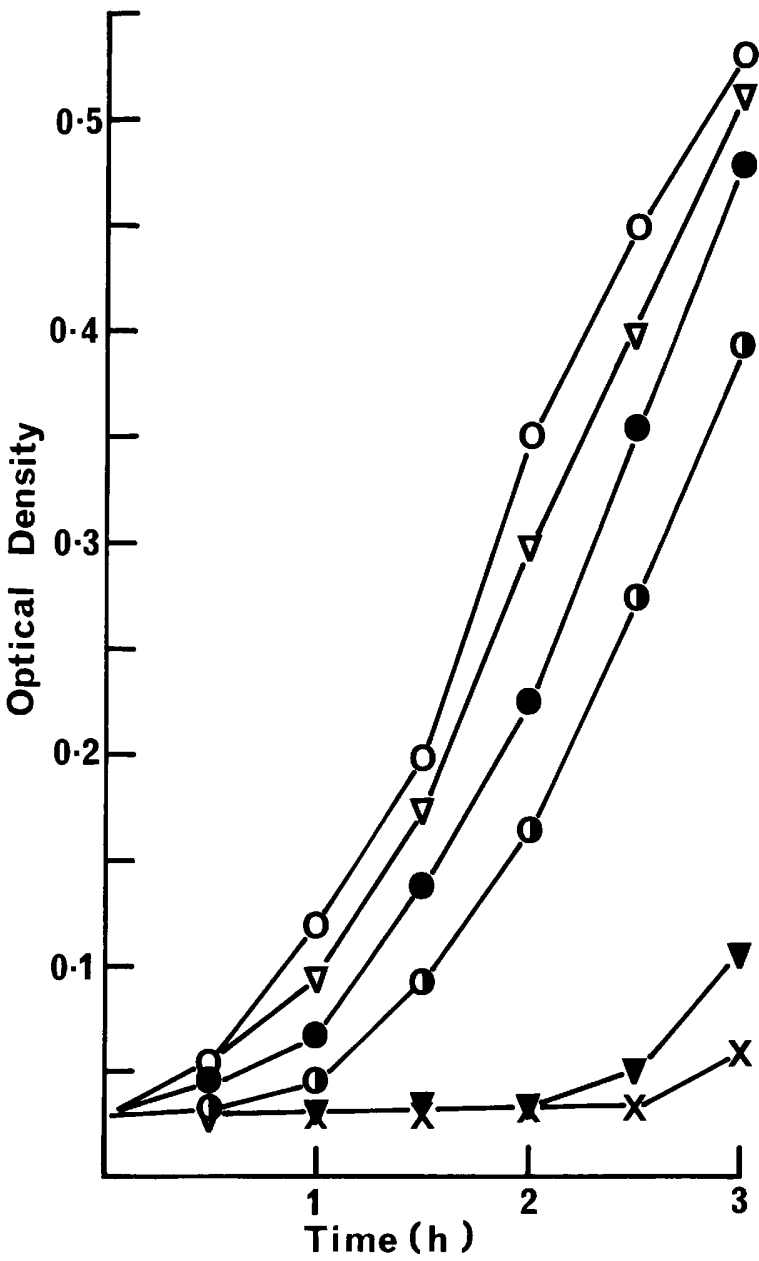

Fig. 3. Growth inhibition after exposure of $E$. coli strains 1829 and $1829 \mathrm{ColV}, \mathrm{I}-\mathrm{K} 94$ to $p \mathrm{H} \mathrm{3.5.} \mathrm{O=strain} 1829$ untreated; $\bullet=$ strain 1829 after 12.5 min at $p \mathrm{H} 3 \cdot 5 ; \mathrm{O}=$ strain 1829 after 16 min at $p \mathrm{H} 3 \cdot 5 ; \nabla=$ strain $1829 \mathrm{ColV}, \mathrm{I}-\mathrm{K} 94$ untreated; $\nabla=$ strain 1829 ColV,I-K94 after $12.5 \mathrm{~min}$ at $p \mathrm{H} 3.5 ; \mathrm{X}=1829 \mathrm{ColV}, \mathrm{I}-\mathrm{K} 94$ after 16 min at $p \mathrm{H} 3 \cdot 5$. Organisms grown throughout in broth at $37^{\circ} \mathrm{C}$, shaken.

Neither strain grew or changed the $p \mathrm{H}$ during incubation for $3.5 \mathrm{~h}$ at $37^{\circ} \mathrm{C}$ in broth of initial $p \mathrm{H}$ $\leq 4 \cdot 3$. Both strains grew slightly in broth initially at $p \mathrm{H} 4.4$ or 4.5 and substantial growth of both strains occurred at $p \mathrm{H} \geq 4 \cdot 6$.

Growth in urine was poor. With an inoculum of c. $3 \times 10^{10}$ organisms/L, neither $E$. coli strain 1829 nor strain 1829 ColV,I-K94 grew appreciably during incubation for $24 \mathrm{~h}$ in urine of which the initial $p \mathrm{H}$ was $4 \cdot 5$. Cell mass (dry weight $/ \mathrm{ml}$ ) approximately doubled for both strains when the initial $p \mathbf{H}$ was 5.0 . Better growth was achieved at $p \mathrm{H} 5.5$ and 6.5 but there appeared to be little difference between the parent $E$. coli and its ColV,I-K94+ derivative. 


\section{Discussion}

ColV plasmids confer or enhance several bacterial properties that may be related to virulence. Amongst these properties, the production of ironchelating components does not depend on derepressed transfer properties and the same may be true for increased resistance to complement (Nilius and Savage, 1984). In contrast, adhesion properties (Clancy and Savage, 1981), increased surface hydrophobicity (Tewari et al., 1985) and autoagglutination, which may impede phagocytosis and killing by inhibitory agents (Rowbury et al., 1985), depend on derepressed transfer properties. Accordingly, maintenance of these potential virulence properties depends on the plasmid transfer properties being derepressed. The results described here indicate that as well as conferring beneficial effects, the ColV plasmids expose the host bacterium to extreme acid sensitivity. This sensitivity is due to the presence of the plasmid and not to its introduction into an acidsensitive variant because curing the plasmid reduced acid-sensitivity to that of the parental $\mathrm{Col}^{-}$ strain (table I). The acid sensitivity appears to depend on the presence of transfer components because factors that lead to loss or repression of transfer properties, reduced or abolished the acid sensitivity conferred by ColV plasmids (tables III and IV). The effects of transfer components is specific for individual plasmids because R124-F2 conferred marked acid sensitivity whereas Flac had no effect. The sensitising effect conferred by ColVK98 must depend on some other component because transfer properties of this plasmid are repressed. The transfer components may confer acid sensitivity by allowing hydrogen ions to cross the outer membrane more readily. The tight packing of the lipopolysaccharide (LPS) molecules maintains the impenetrability of the outer membrane to many inhibitory agents and insertion of transfer components into the outer membrane may weaken LPS-LPS bonds, as has been suggested for compounds with strongly cationic regions (Hancock, 1984). This could then allow increased permeation and acid killing. Alternatively, certain transfer components (e.g., pili) might act as pores to allow increased acid permeation across the outer membrane.

Increased acid sensitivity encoded by the ColV plasmids tested would reduce survival of $\mathrm{ColV}^{+}$ organisms on exposure to gastric acid to the acid environment in phagolysosomes. ColV ${ }^{+}$survivors might also be sensitised to the effects of other inhibitory agents, as we observed here with $\mathrm{H}_{2} \mathrm{O}_{2}$ (table V).

The ColV plasmids had no marked effect on growth in broth or urine at the acid $p \mathrm{H}$ values $(5 \cdot 0$ 6.0) commonly found in urine. Accordingly, the virulence characteristics aiding survival in this situation, e.g., adhesion properties, are not counterbalanced by detrimental effects in relation to $\mathrm{pH}$.

\section{REFERENCES}

Binns M M, Davies D L, Hardy K G 1979 Cloned fragments of the plasmid ColV,I-K94 specifying virulence and serum resistance. Nature 279: 778-781.

Binns M M, Mayden J, Levine R P 1982 Further characterization of complement resistance conferred on Escherichia coli by the plasmid genes traT of R100 and iss of ColV, I-K94. Infection and Immunity 35:654-659.

Clancy J, Savage D C 1981 Another colicin V phenotype; in vitro adhesion of Escherichia coli to mouse intestinal epithelium. Infection and Immunity 32:343-352.

Fredericq P, Joiris E 1950 Distribution des souches productrices de colicine $\mathbf{V}$ dans selles normales et pathologiques. Comptes Rendus des Seances de la Société de Biologie Paris. 144:435-437.

Hancock, R E W 1984 Alterations in outer membrane permeability. Annual Reviews of Microbiology 38:237-264.

Hardy, K G 1975 Colicinogeny and related phenomena. Bacteriological Reviews 39:464-515.

Jensen M S, Bainton D F 1973 Temporal changes in $p H$ within the phagocytic vacuole of the polymorphonuclear neutrophilic leukocyte. Journal of Cell Biology, 56:379-388.

Mims, C A 1982 The pathogenesis of infectious disease 2nd edn. Academic Press, London.
Moores J C, Rowbury R J 1982 A new major outer membrane protein in derivatives of Escherichia coli carrying the virulence plasmid ColV,-K94. Zeitschrift für Allgemeine Mikrobiologie 22:465-475.

Nilius A M, Savage D C 1984 Serum resistance encoded by Colicin V plasmids in Escherichia coli and its relationship to the plasmid transfer system. Infection and Immunity 43:947953.

Rous P 1925 The relative reaction within living mammalian tissues; on the mobilization of acid material within cells and the reaction as influenced by the cell state. Journal of Experimental Medicine, 41:399-411.

Rowbury R J, Deeney C M, Reakes C, Rossouw F T, Smith D G, Tewari R 1985 Envelope protein changes, autoagglutination, sensitivity to hydrophobic agents and a conditional division lesion in Escherichia coli strains carrying Colv virulence plasmids. Annales de l'Institute Pasteur, 136A : $147-157$.

Taylor P W 1983 Bactericidal and bacteriolytic activity of serum against gram-negative bacteria. Microbiological Reviews 47:46-83.

Tewari R, Smith D G, Rowbury R J 1985 Effect of ColV plasmids on the hydrophobicity of Escherichia coli. FEMS Microbiology Letters 29:245-249.

Williams P H 1979 Novel iron uptake system specified by ColV 
plasmids: an important component in the virulence of invasive strains of Escherichia coli. Infection and Immunity 26:925-932.

Williams Smith H 1974 A search for transmissible pathogenic characters in invasive strains of Escherichia coli: the discovery of a plasmid-controlled toxin and a plasmid-con- trolled lethal character closely associated, or identical, with colicine V. Journal of General Microbiology 83:95-111.

Williams Smith H, Huggins M B 1976 Further observations on the association of the colicine $\mathrm{V}$ plasmid of Escherichia coli with pathogenicity and with survival in the alimentary tract. Journal of General Microbiology 92:335-350. 